\title{
How hypertensive patients in the rural areas use home blood pressure monitoring and its relationship with medication adherence: A primary care survey in China
}

\author{
Huanhuan $\mathrm{Hu}^{1}$, Gang $\mathrm{Li}^{2}$, Takashi $\mathrm{Arao}^{3^{*}}$ \\ ${ }^{1}$ Lab of Exercise Epidemiology, Graduate School of Sport Sciences, Waseda University, Saitama, Japan \\ ${ }^{2}$ Institute of Chronic Diseases Control and Prevention, Beijing Center for Diseases Control and Prevention, Beijing, China \\ ${ }^{3}$ Lab of Exercise Epidemiology, Faculty of Sport Sciences, Waseda University, Saitama, Japan; \\ Corresponding Author: tarao@waseda.jp
}

Received 7 October 2013; revised 8 November 2013; accepted 19 November 2013

Copyright (C) 2013 Huanhuan $\mathrm{Hu}$ et al. This is an open access article distributed under the Creative Commons Attribution License, which permits unrestricted use, distribution, and reproduction in any medium, provided the original work is properly cited.

\begin{abstract}
Despite an increasing popularity of home blood pressure monitoring (HBPM) over the last few decades, little is known about HBPM use among hypertensive patients in the rural areas. A crosssectional survey including $\mathbf{3 1 8}$ hypertensive patients was conducted in a rural community in Beijing, China, in 2012. Participants were mainly recruited from a community health clinic and completed the questionnaires assessing HBPM usage. Binary logistic regression models were used for the analysis of medication adherence with age, gender, level of education marital status, perceived health status, duration of hypertension, HBPM use, and frequency of performing BP measurement. Among the total population, $78(24.5 \%)$ reported currently use of HBPM. Only $5.1 \%$ of the HBPM users cited doctor's advice as the reason for using HBPM. Analysis of the risk factors of poor medication adherence by multivariable modeling indicated significant associations between the duration of hypertension (adjusted OR, 3.31; 95\% Cl, 1.91 - 5.72; $P<0.001$ ), frequency of performing BP measurements (adjusted OR, 2.33; 95\% Cl, 1.42 - 3.83; $P<0.001$ ) and medication adherence. We found that most use of HBPM was without the involvement of a doctor or nurse. Further study is required to understand if HBPM is effective and the role of health professionals in its use for improved hypertension control.
\end{abstract}

Keywords: Hypertension; Home Blood Pressure
Monitoring; Medication Adherence

\section{INTRODUCTION}

Hypertension is a major public health problem due to its high prevalence worldwide and concomitant risk for cardiovascular disease [1,2]. In China, the number of patients with cardiovascular diseases is estimated to be 230 million, of whom 200 million have hypertension [3]. However, the control of hypertension is relatively poor. A survey conducted in southern China showed that $13.5 \%$ of hypertensive patients living in urban regions controlled their hypertension; this proportion was higher than that in rural regions $(3.4 \%)$ [4]. Considering that approximately $57 \%$ of the total population in China resides in the rural areas, the largest number of hypertensive patients reside in rural areas as well [5]. Poor management of hypertension in rural areas has led to a heavy burden on public health in China. A greater increase in cardiovascular disease mortality in rural residents was found in comparison to urban residents [1]. Self-care behaviors have been documented as one of the main determinants of hypertension control [6-9]. To date, little is known about how patients in rural areas use self-care strategies to manage BP at home.

One form of self-care, home blood pressure monitoring (HBPM), is becoming increasingly popular among hypertensive patients [10-12]. Evidence of the utility and benefits of HBPM is continually being reported [13-17]. The adoption of HBPM has been recommended for people with hypertension in conjunction with their health care professionals in order to achieve a specific level of BP control and prevent cardiovascular events $[6,18]$. 
HBPM can be used to aid in adjusting a therapeutic regimen in response to BP levels and may help individuals adjust their dietary intake, physical activity, and medication use more appropriately $[19,20]$. Given the substantial mortality, morbidity, and cost associated with poorly controlled BP, research on HBPM, which is considered a low-cost strategy to improve hypertension control, should be given high priority.

In China, there is paucity of information on HBPM usage among the rural hypertensive population. Studying the use of HBPM is important because it can provide vital information for the development of suitable training programs, suggest practical action, and provide inputs on how to promote regular BP monitoring. The objectives of this study reported were to 1) explore how and why patients adopt HBPM, and 2) examine the association between HBPM and medication adherence.

\section{METHODS}

In 2012, we conducted a cross-sectional survey in a rural community in Beijing, China, to obtain data on the self-care behaviors of hypertensive patients.

\subsection{Study Participants}

Details of the study have been reported elsewhere [21]. Eligible participants were aged $\geq 35$ years and having hypertension for at least 12 months. Hypertension is defined as an average systolic BP (SBP) $\geq 140 \mathrm{~mm} \mathrm{Hg}$, an average diastolic BP (DBP) $\geq 90 \mathrm{~mm} \mathrm{Hg}$, and/or selfreported current treatment for hypertension with antihypertensive medication [6]. Participants who could not communicate effectively with the study personnel or provide informed consent were excluded. A total of 890 hypertensive patients were registered in the community health clinic. One hundred and forty-three patients who did not provide contact information were excluded from the study. Of the remaining 747 patients, 456 patients met the inclusion criteria and were invited to participate in this study via telephone. As some hypertensive patients may have not attended the health clinic and were not registered, we also recruited subjects through wordof-mouth and put up a poster in the community to create awareness about the study.

Briefly, 523 individuals were invited to participate in the study. Of these, 456 were registered patients. An additional 41 individuals were recruited by referral from study participants who were already recruited, and 26 joined after viewing a poster advertisement in the community. Eligibility was assessed by the physicians at the study sites. After exclusion or drop out from the study, a final study population of 318 patients (289 recruited from registration, 17 from referral, and 12 from the poster advertisement) completed the questionnaire.

\subsection{Questionnaire}

The questionnaire was administrated verbally to the participants by trained interviewers at the study site, and interviews lasted for 20 minutes on an average. Respondents were categorized as HBPM users if they responded "yes" to the question, "Do you currently use a HBPM to evaluate your BP?" Participants who reported using a publicly available automated BP monitor stationed in stores were considered HBPM nonusers. Other survey questions queried about the frequency of BP measurements taken per week and per month, the type of monitor, where the monitor was obtained from, and their reasons for using an HBPM device.

\subsection{Anthropometrics}

All anthropometric measurements were carried out by trained field workers in the morning based on WHO recommendations [22]. Height was measured to the nearest $0.5 \mathrm{~cm}$ and weight, to the nearest $0.1 \mathrm{~kg}$. Body mass index (BMI) was calculated as kilograms per meter squared $\left(\mathrm{kg} / \mathrm{m}^{2}\right)$. BMI was categorized as either normal weight $\left(18.5-23.9 \mathrm{~kg} / \mathrm{m}^{2}\right)$, overweight $(24.0-27.9$ $\left.\mathrm{kg} / \mathrm{m}^{2}\right)$, obese $\left(\geq 28.0 \mathrm{~kg} / \mathrm{m}^{2}\right)$ according to the Chinese BMI criteria [23].

\subsection{Medication Use}

Adherence to prescribed medication was tested using 5questions. Participants were asked to describe their physician-prescribed dose of antihypertensive medications, and their actual medication intake at home. For example, participants were asked, "How many types of medications were prescribed by your physician?" and "What is the prescribed dosage for each medication?" The prescribed dose was compared with the actual amount of medication intake at home. Participants who reported taking antihypertensive medications as prescribed were considered good adherents, and all others were poor adherents [21].

\subsection{Data Management and Statistical Analysis}

Data were double-entered and crosschecked using the Epi Info version 6 statistical software. Participants with missing values were excluded from the analysis. Descriptive statistics were used to calculate percentages and mean values. Student's t-tests, Pearson's $\chi^{2}$-tests, and Fisher's exact tests, as appropriate, were used to assess the associations between HBPM users and nonusers. We performed an exploratory analysis to determine whether demographic and clinical variables were associated with medication adherence (good or poor). The risk factors explored were age, gender, level of education, marital 
status, perceived health status, duration of hypertension, HBPM use, and frequency of BP measurement. Binary logistic regression models were used, and all factors were studied in univariable and multivariable analyses. Values were considered to be statistically significant at $P$ $=0.05$. All statistical analyses were performed using IBM SPSS, version 19 (SPSS Inc., Chicago, IL, USA).

\subsection{Ethical Considerations}

This study was approved by the Ethical Review Board at Waseda University. Written informed consent was obtained from all the participants prior to data collection. Participants were informed they could stop the interview at any time and decline to answer questions without giving a reason.

\section{RESULTS}

\subsection{Characteristics of the Sample}

Demographic and clinical characteristics of the total population $(\mathrm{N}=318)$ are shown in Table 1. The majority of participants were female $(71.7 \%)$, overweight or obese (72.4\%), and non-smokers (79.2\%). Participants had a mean age of $62.9( \pm 9.8)$ years (range, 35 - 83 years), and the number of years with hypertension ranged from 1 to 41 , with a mean of $8.2( \pm 7.1)$ years. Approximately $25.2 \%$ of all participants rated their health as good to very good, and $19.2 \%$ reported the presence of diabetes. The average time reported since last BP measurement was $23.3( \pm 40.1)$ days.

Of the 318 participants, $78(24.5 \%)$ reported current use of a HBPM device. Approximately $75 \%$ reported measuring their BP most frequently in public at a community clinic or drug store. Patients using HBPM reported a shorter length of time since their last measurement than nonusers $(P=0.006)$. No significant differences in ethnicity, annual family income, education level, gender, and medication adherence were found between HBPM users and nonusers; however, patients using HBPM had a higher level of education than nonusers $(37.2 \%$ vs $27.9 \%, P=0.155)$ and better medication adherence $(62.8 \%$ vs $60.8 \%, P=0.790)$; there were also more women than men in this group $(26.8 \%$ vs $18.9 \%, P$ $=0.151)$.

\subsection{Type and Source of Home BP Monitors}

The majority of participants using HBPM (66.2\%) reported having a mercury sphygmomanometer, and $33.8 \%$ reported using an automatic HBPM device. Most HBPM devices were purchased at a pharmacy or department store, or were provided by a family member $(15.6 \%)$. A smaller number of participants purchased their monitor via the Internet $(5.2 \%)$ or obtained their monitor from a friend/colleague (5.2\%) (Table 2).
Table 1. Demographic and clinical characteristics of study population.

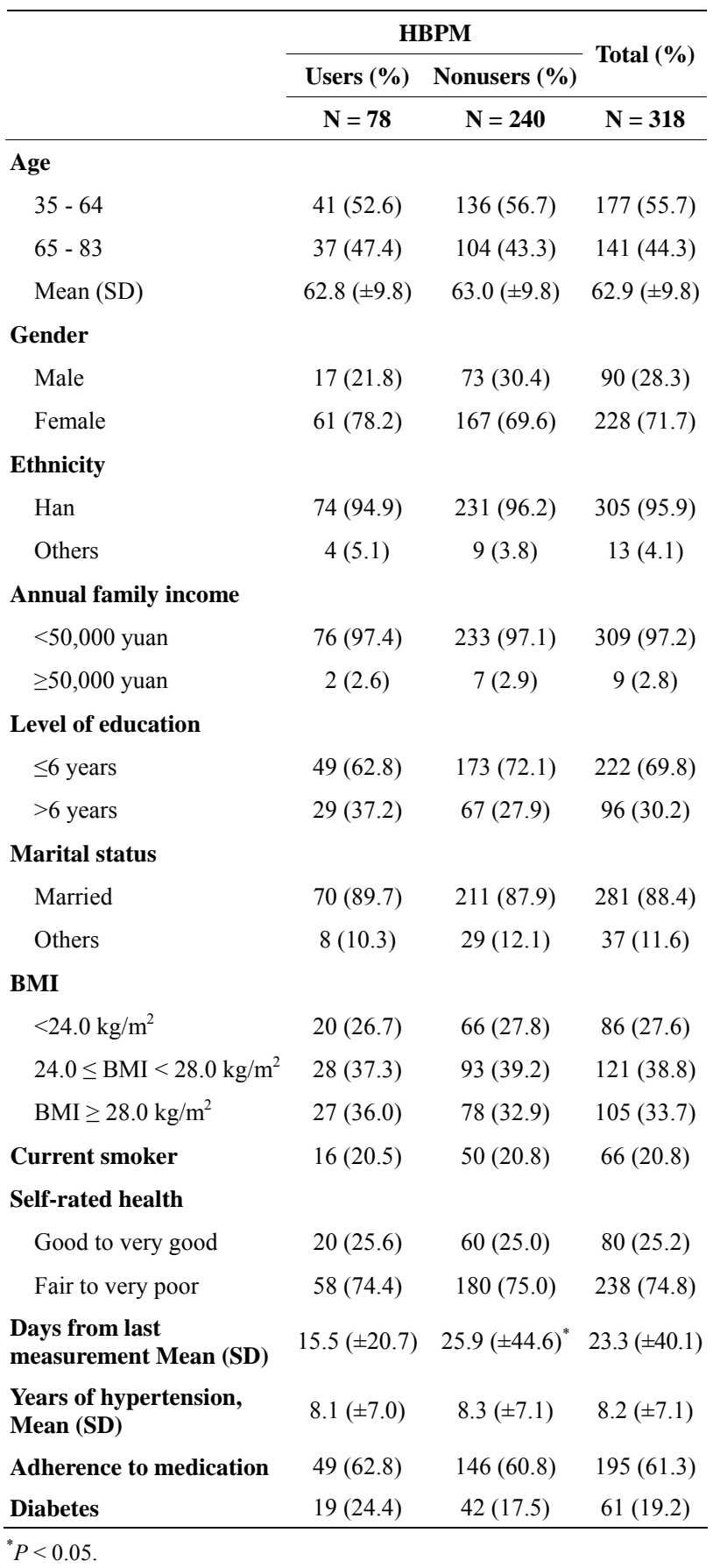

\subsection{Reasons forlnot Using HBPMs}

Among patients who reported using HBPM, almost half $(48.7 \%)$ cited their primary reason as personal motivation for monitoring their BP, and $42.3 \%$ indicated that they used HBPM because they already had monitors in their home. Only 5.1\% were advised to use a HBPM device by their doctor. Among the nonusers, the majority $(44.7 \%)$ did not understand how to operate the device, 
Table 2. Use of home blood pressure monitoring among hypertensive patients.

\begin{tabular}{lc}
\hline & $\mathrm{N}(\%)$ \\
\hline Source of monitor $(\mathbf{N}=\mathbf{7 7})$ & $34(44.2)$ \\
Pharmacy & $14(18.2)$ \\
Departmental store & $4(5.2)$ \\
Internet & $12(15.6)$ \\
Family members & $4(5.2)$ \\
Friends/colleagues & $9(11.7)$ \\
Other & \\
Reason for practising HBPM (N = 78) & $4(5.1)$ \\
Advised by doctor & $33(42.3)$ \\
For monitoring & $38(48.7)$ \\
Already had access & $3(3.8)$ \\
Other & \\
Reason for not practising HBPM (N = 208) & $38(16.8)$ \\
Economic difficulty & $101(44.7)$ \\
Do not understand or know how & $19(8.4)$ \\
Not important for him & $68(30.1)$ \\
Other &
\end{tabular}

$16.8 \%$ were unable to afford the device, and $8.4 \%$ did not think carrying out home BP measurements was important. Other reasons for not using HBPM included the accessibility of BP monitors at the community clinics and local stores or never having heard of HBPM devices (Table 2).

\subsection{Frequency of Performing BP Measurement}

Only $6.4 \%$ of HBPM users indicated measuring their BP every day or almost every day; however, $58.9 \%$ reported measuring their BP at least a few times per month and $10.2 \%$ stated rarely using their monitor. Among nonusers, a very small percentage $(0.8 \%)$ indicated that they measure their BP every day or almost every day at the community clinical center and drug store, $42.2 \%$ measure their BP at least a few times per month, and nearly $29.2 \%$ rarely measure their BP. Significant difference in the frequency of BP measurement was found ( $P$ $<0.001$ ) between HBPM users and nonusers (Table 3).

\subsection{Factors Associated with Medication Adherence}

In the univariable analysis, there was a statistically significant, increased risk of poor medication adherence for those with a shorter duration of hypertension and lower frequency of BP measurements (Table 4). After
Table 3. Frequency of performing blood pressure measurement in patients practising HBPM and not practising HBPM.

\begin{tabular}{cccc}
\hline & \multicolumn{2}{c}{ HBPM } & Total (\%) \\
\cline { 2 - 3 } & Users (\%) & Nonusers (\%) & \\
\cline { 2 - 3 } & $\mathrm{N}=78$ & $\mathrm{~N}=240$ & $\mathrm{~N}=318$ \\
\hline $\begin{array}{c}\text { Every day or almost } \\
\text { every day }\end{array}$ & $5(6.4)$ & $2(0.8)$ & $7(2.2)$ \\
$\begin{array}{c}\text { Once or more per week } \\
\text { but not every day }\end{array}$ & $31(39.7)$ & $36(15.0)$ & $67(21.1)$ \\
$\begin{array}{c}\text { Twice or trice per month } \\
\text { Once per month }\end{array}$ & $15(19.2)$ & $52(21.7)$ & $67(21.1)$ \\
A few times per year & $5(24.3)$ & $80(33.3)$ & $99(31.1)$ \\
Less than twice per year & $3(3.8)$ & $35(14.6)$ & $40(12.6)$ \\
\hline
\end{tabular}

adjustment for all potential risk factors of poor adherence, duration of hypertension and frequency of BP measurement were significantly associated with adherence. For a duration of hypertension longer than 3 years, the odds of better adherence increased by 2.31 (adjusted OR, 3.31; 95\% CI, 1.91 - 5.72; $P<0.001)$. Patients who measured BP twice per month or more also tended to have a better adherence (adjusted OR, 2.33; 95\% CI, 1.42 - 3.83; $P<$ $0.001)$.

\section{DISCUSSION}

Although the significance and importance of HBPM for hypertensive control have been well understood, only a limited number of surveys on the prevalence of HBPM among hypertensive patients are available. Moreover, most of these studies were carried out in developed countries. The prevalence of HBPM in this study was $24.5 \%$, which was lower than that in developed countries with a prevalence of $43.0 \%$ [12] and 74.7\% [11]. Previous studies reported that patients with a higher education level, higher income, and younger age were more likely to adopt HBPM [10,24-26]. Patients in our study lived in the rural areas in China and were typically older $(62.9 \pm$ 9.8 years) with lower education levels ( $\leq 6$ years; $69.8 \%$ ) than those reported in the previous studies [10, 24-26]. Therefore, the lower prevalence of HBPM in this study could be partially due to these participants' socioeconomic status and demographic characteristics. A similar lower prevalence $(24.0 \%)$ of HBPM was recently reported in Singapore [24]. This finding in our study suggests that more health care and social supports should be provided to the hypertensive patients in rural areas in China.

Many of the limitations of traditional BP measurements outside of the home are overcome by HBPM use; however, $75 \%$ of our patients measured their BP at a community clinic or store. Respondents' reasons for not using HBPM provide some clues to this phenomenon. 
Table 4. Determinants of medication adherence.

\begin{tabular}{|c|c|c|c|c|}
\hline & Poor adherence & Good adherence & Non-adjusted $\mathrm{OR}^{\mathrm{a}}$ & $P$ \\
\hline & $\mathrm{N}=123(\%)$ & $\mathrm{N}=195(\%)$ & $(\mathrm{CI} 95 \%)$ & \\
\hline \multicolumn{5}{|l|}{ Age } \\
\hline $35-64$ & $73(59.3)$ & $104(53.3)$ & $0.78(0.50,1.24)$ & 0.293 \\
\hline $65-83$ & $50(40.7)$ & $91(46.7)$ & 1 & \\
\hline \multicolumn{5}{|l|}{ Gender } \\
\hline Male & $35(28.5)$ & $55(28.2)$ & $0.99(0.60,1.63)$ & 0.962 \\
\hline Female & $88(71.5)$ & $140(71.8)$ & 1 & \\
\hline \multicolumn{5}{|l|}{ Level of education } \\
\hline$>6$ years & $43(35.0)$ & $53(27.2)$ & $0.69(0.43,1.13)$ & 0.142 \\
\hline$\leq 6$ years & $80(65.0)$ & $142(72.8)$ & 1 & \\
\hline \multicolumn{5}{|l|}{ Self-rated health } \\
\hline Good to very good & $33(26.8)$ & $47(24.1)$ & $0.87(0.52,1.45)$ & 0.585 \\
\hline Fair to very poor & $90(73.2)$ & $148(75.9)$ & 1 & \\
\hline \multicolumn{5}{|l|}{ HBPM use } \\
\hline Yes & $29(23.6)$ & $49(25.1)$ & $1.09(0.64,1.84)$ & 0.754 \\
\hline No & $94(76.4)$ & $146(74.9)$ & 1 & \\
\hline \multicolumn{5}{|l|}{ Years of hypertension } \\
\hline$\geq 3$ years & $77(62.6)$ & $165(84.6)$ & $3.29(1.93,5.60)$ & $<0.001$ \\
\hline$<3$ years & $46(37.4)$ & $30(15.4)$ & 1 & \\
\hline \multicolumn{5}{|c|}{ Frequency of BP measurement } \\
\hline$\geq 2$ times per month & $39(31.7)$ & $102(52.3)$ & $2.36(1.47,3.79)$ & $<0.001$ \\
\hline$<2$ times per month & $84(68.3)$ & $93(47.7)$ & 1 & \\
\hline
\end{tabular}

The low level of literacy (not knowing how to operate the device) among our study population is one possible explanation. Additionally, community clinics and stores are an accessible resource for measuring BP levels. Although the utilization of BP monitors in community health centers for hypertensive patients has been previously assessed [27], there are little data about the use of monitors stationed in stores. Further investigation is needed to determine whether monitors available in stores are reliable and easily accessible for BP measurement as well as whether these monitors can be used for hypertension management in rural areas.

More than half $(66.2 \%)$ of our participants who self-monitored their BP levels used a manual BP device, whereas the remaining $33.8 \%$ of participants used automatic devices. This is contrary to other findings from developed countries $[12,26]$. One possible reason is that automatic electronic BP devices are more expensive for people in rural areas. Another possible reason is that patients believe that manual devices are more reliable than the widely varying automated electronic BP monitors [28]. One study found a proportion of automated BP monitors used in a community inaccurate [29]. Instructions for automated devices regarding calibration, use, and target treatment should be provided to the hypertensive patients [25], although the optimum scheme of using
HBPM devices needs further clarification.

Respondents' reasons for using HBPMs imply that most use them for self-monitoring without guidance from medical or nursing staff. Only $5.1 \%$ of the HBPM users cited doctor's advice as the reason for adopting HBPM use. Most respondents indicated that they monitored their BP because of personal interest. Self-monitoring of BP should be performed as a partnership between patients and health professionals for maximum benefit $[18,25]$. Therefore, physicians in rural areas should consider asking if a hypertensive patient is using HBPM and offer guidance on how patients can best use this self-care strategy to improve or maintain BP control.

Among HBPM users and nonusers, there is considerable variation in the frequency of BP measurements. This finding was similar to that of other studies $[12,26]$. The duration of hypertension, control level, and a variety of personal factors probably influence the frequency of BP monitoring [12]. Our results showed that approximately $34.5 \%$ of HBPM users reported measuring their BP once per month or not at all at home. We believe that physician consultation and guidance regarding proper HBPM use would increase the frequency of using HBPM to measure BP.

Exploratory analyses of risk factors of poor adherence by multivariable modeling indicated significant associa- 
tions between the duration of hypertension, frequency of BP measurement, and medication adherence. Specifically, we found a decrease in the risk of poor adherence for patients with longer durations of hypertension and those who more frequently monitored their BP. However, the use of HBPM was not significantly associated with medication adherence. Although data on the effects of HBPM on patients' medication intake are inconsistent, it was noted that all the studies that utilized self-report measures or pharmacy refill data reported negative findings [30]. Our negative finding may be partly attributed to the self-reported method used to measure medication adherence. When HBPM was used with other interventions, including patient counseling and education, its efficacy for adherence was greater [30]. In our study, very few HBPM users were advised to use HBMP by their doctors. To improve the benefits of HBPM, doctors and nurses should be aware of HBPM use among their patients in order to advise and educate them appropriately.

\section{LIMITATIONS}

The limitations of this study should be highlighted. First, this study was conducted in a single center on hypertensive patients making generalization to other population difficult. Second, we did not measure the adherence with an objective method of measurement, such as electronic monitoring. Last, we did not ask whether the respondent ever had his/her HBPM device checked by a doctor or nurse.

\section{CONCLUSION}

In this study, $24.5 \%$ of patients in rural areas were practicing HBPM, and most patients used their monitor without the involvement of a health professional. Further studies are required to establish whether a relationship exists between HBPM when used in conjunction with professional guidance for improved hypertension control. Moreover, the role of community health centers and stores with BP monitors as easily accessible resources for BP monitoring in rural areas should be further explored.

\section{REFERENCES}

[1] Kearney, P.M., Whelton, M., Reynolds, K., Muntner, P., Whelton, P.K. and He, J. (2005) Global burden of hypertension: Analysis of worldwide data. The Lancet, 365, 217-223.

[2] Perkovic, V., Huxley, R., Wu, Y., Prabhakaran, D. and MacMahon, S. (2007) The burden of BP-related disease: a neglected priority for global health. Hypertension, 50, 991-997.

http://dx.doi.org/10.1161/HYPERTENSIONAHA.107.09 5497

[3] Hu, S.S, Kong, L.Z., Gao, R.L., Zhu, M.L., Wang, W.,
Wang, Y.J., Wu, Z.S., Chen, W.W. and Liu, M.B. (2012) Outline of the report on cardiovascular disease in China, 2010. Biomedical and Environmental Sciences, 25, 251256.

[4] Ma, W.J., Tang, J.L., Zhang, Y.H., Xu, Y.J., Lin, J.Y., Li, J.S., Lao, X.Q., Tam, W.W., Wong, M.C. and Yu, I.T. (2012) Hypertension prevalence, awareness, treatment, control, and associated factors in adults in southern China. American Journal of Hypertension, 25, 590-596.

http://dx.doi.org/10.1038/ajh.2012.11

[5] Zhang, M., Meng, Y., Yang, Y., Liu, Y., Dong, C., Xiao, J., Zhao, L. and Li, F. (2011) Major inducing factors of hypertensive complications and the interventions required to reduce their prevalence: An epidemiological study of hypertension in a rural population in China. BMC Public Health, 11, 301

http://dx.doi.org/10.1186/1471-2458-11-301

[6] Chobanian, A.V., Bakris, G.L., Black, H.R., Cushman, W.C., Green, L.A., Izzo Jr., J.L., Jones, D.W., Materson, B.J., Oparil, S., Wright Jr., J.T., Roccella, E.J., National Heart, Lung, and Blood Institute Joint National Committee on Prevention, Detection, Evaluation, and Treatment of High Blood Pressure and National High Blood Pressure Education Program Coordinating Committee (2003) The seventh report of the joint national committee on prevention, detection, e valuation, and treatment of high blood pressure: The JNC 7 report. Journal of the American Medical Association, 289, 2560-2572.

http://dx.doi.org/10.1001/jama.289.19.2560

[7] Dickinson, H.O., Mason, J.M., Nicolson, D.J., Campbell, F., Beyer, F.R., Cook, J.V., Williams, B. and Ford, G.A. (2006) Lifestyle interventions to reduce raised blood pressure: A systematic review of randomized control trials. Journal of Hypertension, 24, 215-233. http://dx.doi.org/10.1097/01.hjh.0000199800.72563.26

[8] McManus, R.J., Mant, J., Bray, E.P., Holder, R., Jones, M.I., Greenfield, S., Kaambwa, B., Banting, M., Bryan, S., Little, P., Williams, B. and Hobbs, F.D. (2010) Telemonitoring and self-management in the control of hypertension (TASMINH2): A randomised controlled trial. The Lancet, 376, 163-172. http://dx.doi.org/10.1016/S0140-6736(10)60964-6

[9] Bosworth, H.B., DuBard, C.A., Ruppenkamp, J., Trygstad,T., Hewson, D.L. and Jackson, G.L. (2011) Evaluation of a self-management implementation intervention to improve hypertension control among patients in Medicaid. Translational Behavioral Medicine, 1, 191-199. http://dx.doi.org/10.1007/s13142-010-0007-x

[10] Cuspidi, C., Meani, S., Lonati, L., Fusi, V., Magnaghi, G,. Garavelli, G., Palumbo, G., Pini, C., Vaccarella, A., Parati, G., Leonetti, G., Zanchetti, A. and Lombardy Regional Section of the Italian Hypertension Society (2005) Prevalence of home BP measurement among selected hypertensive patients: Results of a multicenter survey from six hospital outpatient hypertension clinics in Italy. Blood Pressure, 14, 251-256. http://dx.doi.org/10.1080/08037050500210765

[11] Logan, A.G., Dunai, A., McIsaac, W.J., Irvine, M.J. and Tisler, A. (2008) Attitudes of primary care physicians and their patients about home blood pressure monitoring in 
Ontario. Journal of Hypertension, 26, 446-452. http://dx.doi.org/10.1097/HJH.0b013e3282f2fdd4

[12] Viera, A.J., Cohen, L.W., Mitchell, C.M. and Sloane, P.D. (2008) How and why do patients use home blood pressure monitors. Blood Pressure Monitoring, 13, 133-137. http://dx.doi.org/10.1097/MBP.0b013e32830263b7

[13] Verberk, W.J., Kroon, A.A., Kessels, A.G. and de Leeuw, P.W. (2005) Home blood pressure measurement: A systematic review. Journal of the American College of Cardiology, 46, 743-751.

http://dx.doi.org/10.1016/j.jacc.2005.05.058

[14] Cappuccio, F.P., Kerry, S.M., Forbes, L. and Donald, A. (2004) Blood pressure control by home monitoring: Meta-analysis of randomized trials. British Medical Journal, 329, 145-150.

http://dx.doi.org/10.1136/bmj.38121.684410.AE

[15] Cuspidi, C., Meani, S., Fusi, V., Salerno, M., Valerio, C., Severgnini, B., Catini, E., Leonetti, G., Magrini, F. and Zanchetti, A. (2004) Home blood pressure measurement and its relationship with blood pressure control in a large selected hypertensive population. Journal of Human Hypertension, 18, 725-731. http://dx.doi.org/10.1038/sj.jhh.1001737

[16] Bobrie, G., Chatellier, G., Genes, N., Clerson, P., Vaur, L., Vaisse, B., Menard, J. and Mallion, J.M. (2004) Cardiovascular prognosis of masked hypertension detected by blood pressure self-measurement in elderly treated hypertensive patients. Journal of the American Medical Association, 291, 1342-1349.

http://dx.doi.org/10.1001/jama.291.11.1342

[17] Staessen, J.A., Den Hond, E., Celis, H., Fagard, R., Keary, L., Vandenhoven, G., O’Brien, E.T. and Treatment of Hypertension Based on Home or Office Blood Pressure (THOP) Trial Investigators (2004) Antihypertensive treatment based on blood pressure measurement at home or in the physician's office. Journal of the American Medical Association, 291, 955-964. http://dx.doi.org/10.1001/jama.291.8.955

[18] Pickering, T.G., Miller, N.H., Ogedegbe, G., Krakoff, L.R., Artinian, N.T., Goff, D., American Heart Association, American Society of Hypertension and Preventive Cardiovascular Nurses Association (2008) Call to action on use and reimbursement for home BP monitoring: Executive Summary. A joint scientific statement from the American Heart Association, American Society of Hypertension, and Preventive Cardiovascular Nurses Association. Hypertension, 52, 1-9. http://dx.doi.org/10.1161/HYPERTENSIONAHA.107.18 $\underline{9011}$

[19] Abdullah, A. and Othman, S. (2011) The influence of self-owned home blood pressure monitoring (HBPM) on primary care patients with hypertension: A qualitative study. BMC Family Practice, 12, 143.

http://dx.doi.org/10.1186/1471-2296-12-143

[20] Worth, H.B., Powers, B.J., Olsen, M.K., McCant, F.,
Grubber, J., Smith, V., Gentry, P.W., Rose, C., Van Houtven, C., Wang, V., Goldstein, M.K. and Oddone, E.Z. (2011) Home blood pressure management and improved BP control: Results from a randomized controlled trial. Archives of Internal Medicine, 171, 1173-1180. http://dx.doi.org/10.1001/archinternmed.2011.276

[21] Hu, H.H., Li, G. and Arao, T. (2013) Prevalence rates of self-care behaviors and related factors in a rural hypertension population: A questionnaire survey. International Journal of Hypertension, 2013, Article ID: 526949. http://dx.doi.org/10.1155/2013/526949

[22] WHO (1995) World Health Organization: Physical status: The use and interpretation of anthropometry report of a WHO expert committee. WHO Technical Report Series, World Health Organization, Geneva.

[23] Chen, C. and Lu, F.C. (2004) The guidelines for prevention and control of overweight and obesity in Chinese adults. Biomedical and Environmental Sciences, 17, 1-36.

[24] Tan, N.C., Khin, L.W. and Pagi, R. (2005) Home bloodpressure monitoring among hypertensive patients in an Asian population. Journal of Human Hypertension, 19, 559-564. http://dx.doi.org/10.1038/sj.jhh.1001865

[25] McManus, R.J., Ryan, A., Greenfield, S., Pattison, H.M., Clifford, S., Marriott, J. and Wilson S. (2007) Self measurement of blood pressure: A community survey. Journal of Human Hypertension, 21, 741-743. http://dx.doi.org/10.1038/sj.jhh.1002217

[26] Baral-Grant, S., Haque, M.S., Nouwen, A., Greenfield, S.M. and McManus, R.J. (2012) Self-Monitoring of blood pressure in hypertension: A UK primary care survey. International Journal of Hypertension, 2012, Article ID: 582068. http://dx.doi.org/10.1155/2012/582068

[27] Chai, Y., Xu, H., Wang, W., Liu, B., Yang, D., Fan, H., Song, F. and Lu, Z. (2011) A survey of factors associated with the utilization of community health centers for managing hypertensive patients in Chengdu, China. PLos One, 6, Article ID: e21718. http://dx.doi.org/10.1371/journal.pone.0021718

[28] Wan, Y., Heneghan, C., Stevens, R., McManus, R.J., Ward, A., Perera, R., Thompson, M., Tarassenko, L. and Mant, D. (2010) Determining which automatic digital blood pressure device performs adequately: A systematic review. Journal of Human Hypertension, 24, 431-438. http://dx.doi.org/10.1038/jhh.2010.37

[29] Hahn, L.P., Folsom, A.R., Sprafka, J.M. and Prineas, R.J. (1987) Prevalence and accuracy of home sphygmomanometers in an urban population. American Journal of Public Health, 77, 1459-1461. http://dx.doi.org/10.2105/AJPH.77.11.1459

[30] Ogedegbe, G. and Schoenthaler, A. (2006) A systematic review of the effects of home blood pressure monitoring on medication adherence. Journal of Clinical Hypertension (Greenwich), 8, 174-180. http://dx.doi.org/10.1111/j.1524-6175.2006.04872.x 